\title{
Could digital imaging be an alternative for digital colorimeters?
}

\author{
Caglar, A ; Yamanel, K ; Gulsahi, K ; Bagis, B ; Özcan, M
}

\begin{abstract}
This study evaluated the colour parameters of composite and ceramic shade guides determined using a colorimeter and digital imaging method with illuminants at different colour temperatures. Two different resin composite shade guides, namely Charisma (Heraeus Kulzer) and Premise (Kerr Corporation), and two different ceramic shade guides, Vita Lumin Vacuum (VITA Zahnfabrik) and Noritake (Noritake Co.), were evaluated at three different colour temperatures $(2,700 \mathrm{~K}, 2,700-6,500 \mathrm{~K}$, and $6500 \mathrm{~K})$ of illuminants. Ten shade tabs were selected (A1, A2, A3, A3,5, A4, B1, B2, B3, C2 and C3) from each shade guide. CIE Lab values were obtained using digital imaging and a colorimeter (ShadeEye NCC Dental Chroma Meter, Shofu Inc.). The data were analysed using two-way ANOVA, and Pearson's correlation. While mean $\mathrm{L}^{*}$ values of both composite and ceramic shade guides were not affected from the colour temperature, $\mathrm{L}^{*}$ values obtained with the colorimeter showed significantly lower values than those of the digital imaging $(\mathrm{p}<0.01)$. At combined 2,700-6500 K colour temperature, the means of $a^{*}$ values obtained from colorimeter and digital imaging did not show significant differences ( $p$ $>0.05$ ). For both composite and ceramic shade guides, $L^{*}$ and $b^{*}$ values obtained from colorimeter and digital imaging method presented a high level of correlation. High-level correlations were also acquired for $\mathrm{a}^{*}$ values in all shade guides except for the Charisma composite shade guide. Digital imaging method could be an alternative for the colorimeters unless the proper object-camera distance, digital camera settings and suitable illumination conditions could be supplied. However, variations in shade guides, especially for composites, may affect the correlation.
\end{abstract}

DOI: https://doi.org/10.1007/s00784-009-0329-6

Posted at the Zurich Open Repository and Archive, University of Zurich

ZORA URL: https://doi.org/10.5167/uzh-44683

Journal Article

Published Version

Originally published at:

Caglar, A; Yamanel, K; Gulsahi, K; Bagis, B; Özcan, M (2010). Could digital imaging be an alternative for digital colorimeters? Clinical Oral Investigations, 14(6):713-718.

DOI: https://doi.org/10.1007/s00784-009-0329-6 


\title{
Could digital imaging be an alternative for digital colorimeters?
}

\author{
Alper Caglar • Kivanc Yamanel • Kamran Gulsahi • \\ Bora Bagis • Mutlu Özcan
}

Received: 27 April 2009 / Accepted: 27 July 2009 / Published online: 18 August 2009

(C) Springer-Verlag 2009

\begin{abstract}
This study evaluated the colour parameters of composite and ceramic shade guides determined using a colorimeter and digital imaging method with illuminants at different colour temperatures. Two different resin composite shade guides, namely Charisma (Heraeus Kulzer) and Premise (Kerr Corporation), and two different ceramic shade guides, Vita Lumin Vacuum (VITA Zahnfabrik) and Noritake (Noritake Co.), were evaluated at three different colour temperatures $(2,700 \mathrm{~K}, 2,700-6,500 \mathrm{~K}$, and $6500 \mathrm{~K})$ of illuminants. Ten shade tabs were selected (A1, A2, A3, A3,5, A4, B1, B2, B3, C2 and C3) from each shade guide. CIE Lab values were obtained using digital imaging and a colorimeter (ShadeEye NCC Dental Chroma Meter, Shofu Inc.). The data were analysed using two-way ANOVA, and Pearson's correlation. While mean $L^{*}$ values of both composite and ceramic shade guides were not affected from the colour temperature, $L^{*}$ values obtained with the colorimeter showed significantly lower values than those of
\end{abstract}

\footnotetext{
A. Caglar $\cdot$ K. Yamanel $\cdot$ K. Gulsahi

Faculty of Dentistry, Department of Prosthetic Dentistry,

Başkent University,

Ankara, Turkey

B. Bagis

Faculty of Dentistry, Department of Prosthetic Dentistry,

Karadeniz Technical University,

Trabzon, Turkey

M. Özcan ( $\square)$

Dental Materials Unit, Center for Dental and Oral Medicine,

Clinic for Fixed and Removable Prosthodontics and Dental

Materials Science, University of Zürich,

Zurich, Switzerland

e-mail: mutluozcan@hotmail.com
}

the digital imaging $(p<0.01)$. At combined $2,700-6500 \mathrm{~K}$ colour temperature, the means of $a^{*}$ values obtained from colorimeter and digital imaging did not show significant differences $(p>0.05)$. For both composite and ceramic shade guides, $L^{*}$ and $b^{*}$ values obtained from colorimeter and digital imaging method presented a high level of correlation. High-level correlations were also acquired for $a^{*}$ values in all shade guides except for the Charisma composite shade guide. Digital imaging method could be an alternative for the colorimeters unless the proper objectcamera distance, digital camera settings and suitable illumination conditions could be supplied. However, variations in shade guides, especially for composites, may affect the correlation.

Keywords Colorimeter Colour · Digital imaging · Shade guides

\section{Introduction}

Judging the colour of a surface highly depends on the surface spectral reflectance and the spectral power distribution of the illuminant as well as the light source, time of the day, surrounding conditions and position of the tooth [1-8]. The ideal colour temperature for colour reproduction is $5,500 \mathrm{~K}$. Light at this temperature is considered as "white" light. The incandescent dental unit lamp has an average colour temperature of $3,800 \mathrm{~K}$. For this reason, dental unit lights should not be used during colour selection as they are too bright and cause glare yielding to eye fatigue. Standard illuminant D65 represents a phase of daylight with a correlated colour temperature of approximately $6,500 \mathrm{~K}[3,9,10]$. Illuminant $\mathrm{A}$, on the other hand, 
Table 1 Digital imaging at various colour temperatures of the illuminants and the colorimeter with both composite and ceramic shade guides

\begin{tabular}{|c|c|c|c|c|c|}
\hline & & $2,700 \mathrm{~K}$ & $2,700-6,500 \mathrm{~K}$ & $6,500 \mathrm{~K}$ & Colorimeter \\
\hline \multirow[t]{4}{*}{$L^{*}$} & Charisma & $75.4 \pm 0.8$ & $75.5 \pm 0.8$ & $75.7 \pm 1.0$ & $65.3 \pm 1.0^{\mathrm{a}, \mathrm{b}, \mathrm{c}}$ \\
\hline & Premise & $74.4 \pm 1.5$ & $74.7 \pm 1.8$ & $74.1 \pm 1.6$ & $61.8 \pm 1.4^{\mathrm{a}, \mathrm{b}, \mathrm{c}}$ \\
\hline & Noritake & $77.1 \pm 1.1$ & $78.1 \pm 1.4$ & $75.9 \pm 1.5$ & $67.7 \pm 1.2^{\mathrm{a}, \mathrm{b}, \mathrm{c}}$ \\
\hline & Vita & $77.9 \pm 1.2$ & $76.8 \pm 1.5$ & $76.6 \pm 1.5$ & $66.3 \pm 1.1^{\mathrm{a}, \mathrm{b}, \mathrm{c}}$ \\
\hline \multirow[t]{4}{*}{$A^{*}$} & Charisma & $7.5 \pm 0.8$ & $-3.1 \pm 0.7^{\mathrm{a}}$ & $-19.2 \pm 0.5^{\mathrm{a}, \mathrm{b}}$ & $-0.5 \pm 0.6^{\mathrm{a}, \mathrm{c}}$ \\
\hline & Premise & $7.7 \pm 1.3$ & $-1.4 \pm 0.8^{\mathrm{a}}$ & $-18.7 \pm 0.6^{\mathrm{a}, \mathrm{b}}$ & $-1.8 \pm 0.2^{\mathrm{a}, \mathrm{c}}$ \\
\hline & Noritake & $8.3 \pm 1.3$ & $-0.7 \pm 0.9^{\mathrm{a}}$ & $-18.6 \pm 0.5^{\mathrm{a}, \mathrm{b}}$ & $-0.7 \pm 0.3^{\mathrm{a}, \mathrm{c}}$ \\
\hline & Vita & $6.8 \pm 1.5$ & $-2.8 \pm 0.9^{\mathrm{a}}$ & $-19.0 \pm 0.7^{\mathrm{a}, \mathrm{b}}$ & $-0.6 \pm 0.3^{\mathrm{a}, \mathrm{c}}$ \\
\hline \multirow[t]{4}{*}{$B^{*}$} & Charisma & $66.5 \pm 0.8$ & $41.7 \pm 1.3^{\mathrm{a}}$ & $23.6 \pm 1.9^{\mathrm{a}, \mathrm{b}}$ & $9.5 \pm 1.4^{\mathrm{a}, \mathrm{b}, \mathrm{c}}$ \\
\hline & Premise & $65.8 \pm 0.6$ & $40.7 \pm 1^{\mathrm{a}}$ & $23.0 \pm 1.3^{\mathrm{a}, \mathrm{b}}$ & $7.2 \pm 0.9^{\mathrm{a}, \mathrm{b}}$ \\
\hline & Noritake & $68.9 \pm 0.8$ & $43.0 \pm 1.5^{\mathrm{a}}$ & $26.4 \pm 1.8^{\mathrm{a}, \mathrm{b}}$ & $15.0 \pm 1.2^{\mathrm{a}, \mathrm{b}, \mathrm{c}}$ \\
\hline & Vita & $68.2 \pm 0.9$ & $44.5 \pm 1.6^{\mathrm{a}}$ & $26.6 \pm 1.8^{\mathrm{a}, \mathrm{b}}$ & $13.5 \pm 1.1^{\mathrm{a}, \mathrm{b}, \mathrm{c}}$ \\
\hline
\end{tabular}

The mean values for $L^{*}, a^{*}$ and $b^{*}$ from digital imaging at various colour temperatures of the illuminants and the colorimeter with both composite and ceramic shade guides

${ }^{\text {a }}$ The difference between $2,700 \mathrm{~K}$ is statistically significant $(p<0.01)$

${ }^{\mathrm{b}}$ The difference between $2,700-6,500 \mathrm{~K}$ is statistically significant $(p<0.001)$

${ }^{\mathrm{c}}$ The difference between $6,500 \mathrm{~K}$ is statistically significant $(p<0.001)$

represents light from the full radiator at absolute temperature of 2,856 K, and illuminant F2 represents light from fluorescent lamp with medium colour temperature of 4,230 K. Among these, illuminant A and D65 are commonly recommended.

Tooth colour could be assessed using a shade guide, a spectrophotometer, colorimeter, film-based photography or computer analysis of digital images $[2,8,11-13]$. Unfortunately, common shade guides do not provide sufficient spectral coverage of the colours present in teeth $[10,12$, 14]. In fact, spectrophotometric/colorimetric approach is attractive so it is more commonly used in dentistry, eliminating possible environmental viewing conditions and examiner's experience [11, 14-17]. On the other hand, computer analysis of digital images produced through a digital camera also enables collection of colour values from the images $[9,18,19]$. Systematic error due to translucency and surface curvature could be minimised when chargecoupled device (CCD)-based imaging systems (i.e. digital cameras or spectroradiometers) are used [9]. However, their reliability for different shade guides under different colour temperatures are not known, to date. The objectives of this study, therefore, were to compare the digital imaging method with a colorimeter at different colour temperatures and also to compare the colour parameters for resin composite and ceramic shade guides. The null hypothesis tested were that digital imaging method would correlate well with that of a colorimeter and composite and ceramic shade guides would present similar colour parameters.

\section{Materials and methods}

Shade guides and tabs

Two different resin composite shade guides, namely Charisma (Heraeus Kulzer, Hanau, Germany) and Premise (Kerr Corporation, Orange, CA, USA), and two different ceramic shade guides, Vita Lumin Vacuum (VITA Zahnfabrik, Bad Säckingen, Germany) and Noritake (Noritake Co., Nagoya, Japan), were evaluated at three different colour temperatures $(2,700 \mathrm{~K}, 2,700-6,500 \mathrm{~K}$, and $6,500 \mathrm{~K})$. Shade tabs that existed commonly in all shade

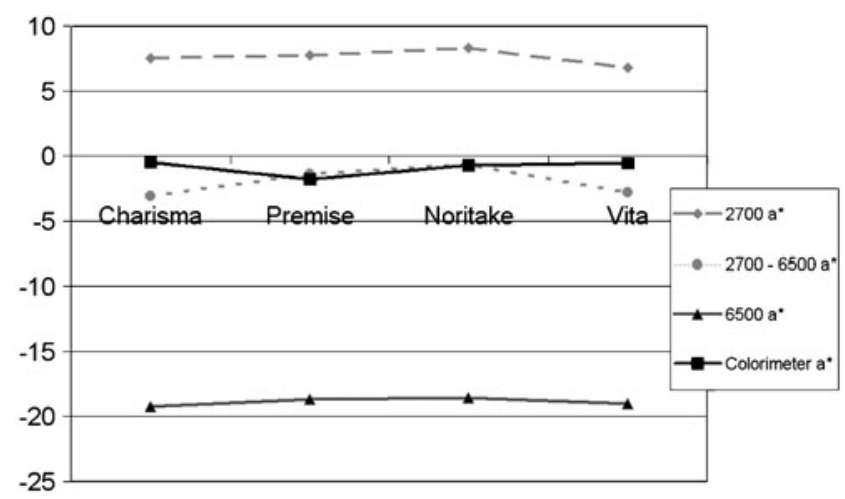

Fig. 1 Mean $a^{*}$ values obtained from both digital imaging method and the colorimeter 
guides (A1, A2, A3, A3,5, A4, B1, B2, B3, C2 and C3) were selected.

\section{Colour measurement}

For digital colour measurement, four fluorescent lamps (each 1,200 $\mathrm{lm}$ ) were mounted perpendicular to the frontal plane of a tailor-made photo stand with lamps being $15 \mathrm{~cm}$ away from the specimen, reflecting at an angle of $45^{\circ}$. Specimens were placed $15 \mathrm{~cm}$ above the stand plane. Digital images were obtained using a digital camera (Fuji S20 Pro, Fujifilm, Tokyo, Japan) adjusted to auto white balance with a CCD sensor having 6.2 million effective pixels. Images were taken from the specimens in an object-

a
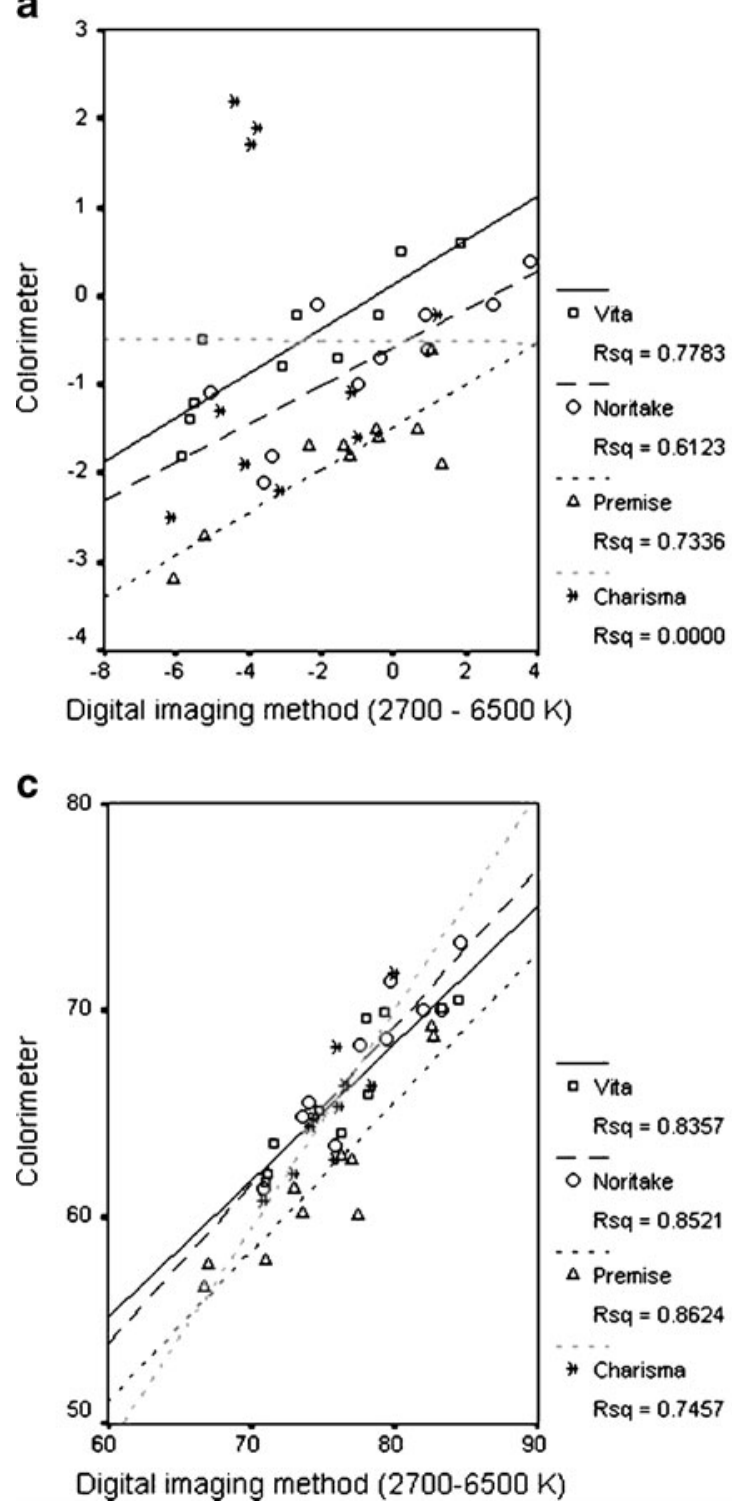

lens distance of $10 \mathrm{~cm}$ in the macro mode using manual settings (aperture: $\mathrm{f} / 11$; shutter speed: $1 / 80 \mathrm{~s}$ ). In the first group, four fluorescent lamps (Philips PL-C 18 W/827, Koninklijke Philips Electronics N.V., Eindhoven, Netherlands) were used with colour temperature of $2,700 \mathrm{~K}$. In the second group, two fluorescent lamps of 6,500 K (Philips PL-C $18 \mathrm{~W} / 865$ ) were placed in the lower socket of the photo stand and combined with two $2,700 \mathrm{~K}$ fluorescent tubes placed in the upper socket. In the third group, four fluorescent lamps were used with colour temperature of $6,500 \mathrm{~K}$.

From each shade tab, three digital images were obtained. Digital images were then transferred to a personal computer (PC), and colour values were calculated using a software

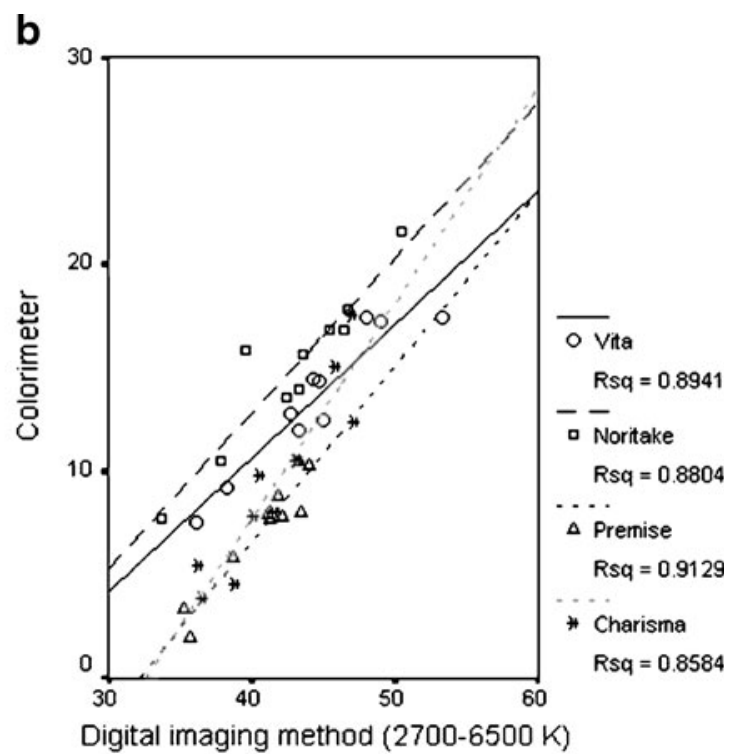

Fig. 2 a-c Correlation between digital imaging $(2,700-6,500 \mathrm{~K})$ and the colorimeter for a $L^{*}$, b $a^{*}$ and $\mathbf{c} b^{*}$ values for both composite and ceramic shade guides 
programme (Adobe Photoshop CS2, Adobe Systems Inc., CA, USA). A measurement template was created in the middle third of the tab that consisted of a spherical area having 3.790 pixels. Colour measurements were made using a histogram tool. The data was obtained in Photoshop red, green and blue (RGB). Mean values were converted from RGB to CIE Lab (Commision Internationale de l'Eclairage, $\left.L^{*}, a^{*}, b^{*}\right)$ values with EasyRGB software (Logicol S.r.l., Trieste, Italy). Colour measurements were made again from all tabs of the shade guides using a digital intraoral colorimeter (ShadeEye NCC Dental Chroma Meter, Shofu Inc., Kyoto, Japan). Before each measurement, the colorimeter was calibrated according to the manufacturer's recommendations. ShadeEye NCC device contains a pulsed xenon lamp as an optical light source and three-component silicon photocell as the optical sensor. The measurements were obtained from each tab by contacting the measurement tip on the middle third region of the shade tabs. Measurements were realised in the analysis mode that gives $L^{*}, a^{*}, b^{*}$ values of the colorimeter.

\section{Statistical analysis}

Statistical analysis was performed using SPSS 11.5 for Windows, (SPSS Inc., Illinois, USA). The means of CIE Lab values of each group were analysed using two-way analysis of variance and Student's $t$ test. Pearson's test was used for the correlations $(\alpha=0.05)$.

\section{Results}

The means of $L^{*}$ values obtained from both composite and ceramic shade guides using the digital imaging did not show significant differences at all colour temperatures $(p>0.01$; Table 1$)$. At $2,700 \mathrm{~K}$, the means of $a^{*}$ and $b^{*}$ values of both composite and ceramic shade guides did not show significant differences $(p>0.01)$ with the digital imaging, but both $a^{*}$ and $b^{*}$ values were significantly affected from the colour temperatures of 2,700-6500 K ( $p<$ $0.01)$ and $6,500 \mathrm{~K}(p<0.001)$. At combined $2,700-6,500 \mathrm{~K}$, the means of $a^{*}$ values obtained from colorimeter and digital imaging did not show significant differences $(p>$ $0.05)$.

Regardless of the shade guide type, mean $a^{*}$ values obtained under $2,700 \mathrm{~K}$ illuminant were more positive (more red), and, under 6,500 $\mathrm{K}$ illuminant, they were more negative (more green; Fig. 1). Within the shade guides, these values were not statistically significant $(p>0.05)$. For both composite and ceramic shade guides, $L^{*}$ and $b^{*}$ values obtained from colorimeter and digital imaging method under each three-colour temperature presented a high level of correlation (Fig. 2a-c). $C^{*} a b$ values were in the order of 2,700 $\mathrm{K}>2,700-6,500 \mathrm{~K}>6,500 \mathrm{~K}>$ colorimeter (Fig. 3a-b). The lowest $L^{*}$ values were obtained with Premise A 3,5. $C^{*} a b$ values of A 3,5 ceramic shade tabs were the highest.

\section{Discussion}

In this study, when the digital imaging was performed only under $2,700-6,500 \mathrm{~K}$, mean $a^{*}$ values did not show significant statistical differences with the colorimeter. High correlation was obtained between the digital imaging and the colorimeter for $L^{*}$ and $b^{*}$ values. Therefore, the hypothesis could be accepted partially. Colorimeter used in this study consists of a pulsed xenon lamp. A xenon arc lamp is a bright white light that closely mimics natural daylight (D65).

When evaluating shade guides by digital imaging method, mean RGB values of three digital images were converted to CIE Lab values. The use of such softwares on PCs has
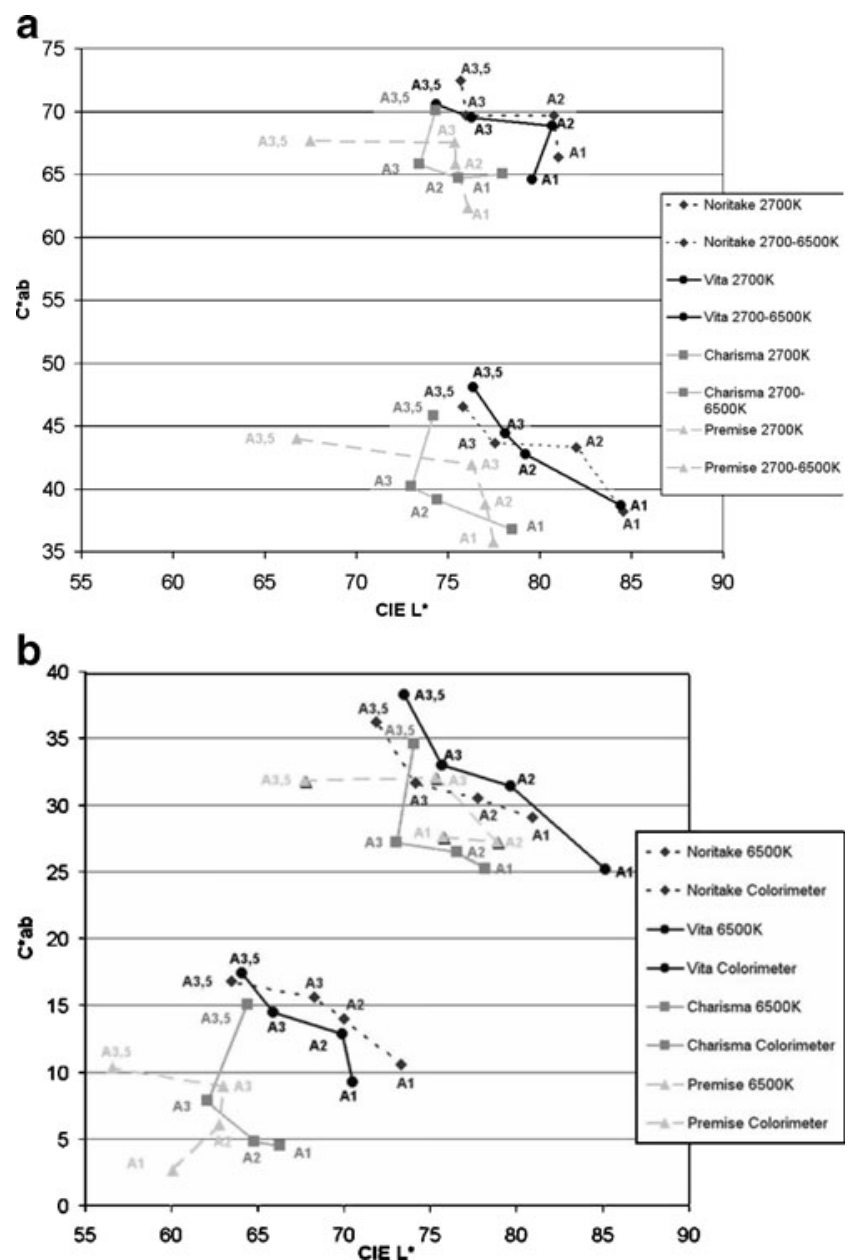

Fig. 3 a-b $L^{*}$ versus $C^{*} a b$ for representative A1, A2, A3 and A3,5 shade tabs obtained at a $2,700 \mathrm{~K}$ and $2700-6500 \mathrm{~K}$ colour temperature using the digital imaging method $\mathbf{b} 6,500 \mathrm{~K}$ colour temperature using the digital imaging method and the colorimeter 
controversial outcome [18-20]. In those studies, the studied material was the tooth brightness and translucency after vital bleaching using $L^{*}$ and RGB values. In earlier studies, intraoral colorimeters have provided accurate and repeatable measurements compared with conventional visual shade selection since the resolution of digital colorimeters is above that of a human eye $[8,9,16,21,22]$. Since standard shade guides without complicated colour blends [17] were used in this study, the results with the colorimeter were consistent, but $b^{*}$ values with the ceramic shade guides were higher with the colorimeter. Variations in $L^{*}, a^{*}, b^{*}$ values are also principally affected due to light transmittance characteristics of the materials [23]. In a similar study, Park et al. [10] evaluated the effect of various illuminants (D65, F2 and A illuminants) on the shade guides (Vita Lumin and Chromascop) using spectrophotometer. The results indicated that $L^{*}$ and $\mathrm{C}^{*} a b$ values were the most affected from the shade and the illuminant. In another study, the type of the standard light source (C, A or D65) had a significant effect of shade guides on the $L^{*}$ values being slightly higher with $\mathrm{C}$ illuminant [24]. In the present study, $L^{*}$ values were similar. This can be due to illuminants being at the same power used in digital imaging method.

In a previous study, only $a^{*}$ and $b^{*}$ colour parameters showed good correlation between digital imaging method and a spectrophotometer [11]. The results of the current study showed good correlation between digital imaging and the colorimeter for all $L^{*}, a^{*}, b^{*}$ values except $a^{*}$ values of Charisma composite shade guide. Although the presence of disparities in $a^{*}$ and $b^{*}$ values were not discussed in the previous study [11], it is most probably related to the chromaticity coordinate of the material. Different filler content of Charisma could be the reason for the disparities in $a^{*}$ values in that more reflection of light during the measurements might have affected the results. This aspect needs to be verified with other shade guides of other composites with other filler particles. In this study, no significant differences were found for the $L^{*}$ values with the digital imaging method. This was most probably because the illuminants had the same power $(72 \mathrm{~W})$. In this study, for the digital imaging method, illuminants on the photo table were placed at $45^{\circ}$ and the camera (observer) at $0^{\circ}$ for better clinical simulation [25]. Verification of the digital imaging versus colorimeter was difficult due to the variations in the light sources and the power, namely xenon lamp, was used by the colorimeter measurements and fluorescent lamp by the digital imaging. Furthermore, ShadeEye NCC device is a self-calibrating apparatus where the calibration is achieved with the calibration cap (docking station) by rotating the device according to the manufacturer. Although it may be considered as a limitation of such studies where spherical area measurements of 3.790 pixels from the digital images cameras were compared with a self-calibrated colorimeter with possible edge loss due to the surface anatomy of shade tabs, standardisation with $45^{\circ}$ illumination, $0^{\circ}$ observation angle and combined 2,700-6,500 $\mathrm{K}$ colour temperature seems to be appropriate to achieve comparable results for the majority of the shade tabs.

\section{Conclusions}

Digital imaging method could be an alternative to the colorimeters when assessing colour in clinical dentistry unless the proper object-camera distance, digital camera settings and suitable illumination conditions are supplied.

Conflict of interest The authors declare that they have no conflict of interest.

\section{References}

1. Knispel G (1991) Factors affecting the process of color matching restorative materials to natural teeth. Quintessence Int 22:525-531

2. Watts A, Addy M (2001) Tooth discolouration and staining: a review of the literature. Br Dent J 190:309-316

3. Fondriest J (2003) Shade matching in restorative dentistry: the science and strategies. Int J Periodont Rest Dent 23:467-479

4. Yang JN, Shevell SK (2003) Surface color perception under two illuminants: the second illuminant reduces color constancy. J Vis 3:369-379

5. Joiner A (2004) Tooth colour: a review of the literature. J Dent 32:3-12

6. Paravina RD, Kimura M, Powers JM (2006) Color compatibility of resin composites of identical shade designation. Quintessence Int 37:713-719

7. Raigrodski AJ, Chiche GJ, Aoshima H, Spiekerman CF (2006) Efficacy of a computerized shade selection system in matching the shade of anterior metal-ceramic crowns - a pilot study. Quintessence Int 37:793-802

8. Dozić A, Kleverlaan CJ, El-Zohairy A, Feilzer AJ, Khashayar G (2007) Performance of five commercially available tooth colormeasuring devices. J Prosthodont 16:93-100

9. Guan YH, Lath DL, Lilley TH, Willmot DR, Marlow I, Brook AH (2005) The measurement of tooth whiteness by image analysis and spectrophotometry: a comparison. J Oral Rehabil 32:7-15

10. Park JH, Lee YK, Lim BS (2006) Influence of illuminants on the color distribution of shade guides. J Prosthet Dent 96:402-411

11. Cal E, Sonugelen M, Guneri P, Kesercioglu A, Kose T (2004) Application of a digital technique in evaluating the reliability of shade guides. J Oral Rehabil 31:483-491

12. Cho BH, Lim YK, Lee YK (2007) Comparison of the color of natural teeth measured by a colorimeter and shade vision system. Dent Mater 23:1307-1312

13. Douglas RD, Steinhauer TJ, Wee AG (2007) Intraoral determination of the tolerance of dentists for perceptibility and acceptability of shade mismatch. J Prosthet Dent 97:200-208

14. Analoui M, Papkosta E, Cochran M, Matis B (2004) Designing visually optimal shade guides. J Prosthet Dent 92:371-376 
15. Douglas RD, Brewer JD (1998) Acceptability of shade differences in metal ceramic crowns. J Prosthet Dent 79:254-260

16. Klemetti E, Matela AM, Haag P, Kononen M (2006) Shade selection performed by novice dental professionals and colorimeter. J Oral Rehabil 33:31-35

17. Li Q, Wang YN (2007) Comparison of shade matching by visual observation and an intraoral dental colorimeter. J Oral Rehabil $34: 848-854$

18. Bentley C, Leonard RH, Nelson CF, Bentley SA (1999) Quantization of vital bleaching by computer analysis of photographic images. J Am Dent Assoc 130:809-816

19. Hasegawa A, Ikeda I, Kawaguchi S (2000) Colour and translucency of in vivo natural central incisors. J Prosthet Dent 83:418-423

20. King KA, deRijk WG (2007) Variations of $L * a * b *$ values among Vitapan classical shade guides. J Prosthodont 16:352-356
21. Okubo SR, Kanawati A, Richards MW, Childress S (1998) Evaluation of visual and instrument shade matching. J Prosthet Dent 80:642-648

22. Dagg H, O'Connell B, Claffey N, Byrne D, Gorman C (2004) The influence of some different factors on the accuracy of shade selection. J Oral Rehabil 31:900-904

23. Arikawa H, Kanie T, Fujii K, Takahashi H, Ban S (2007) Effect of filler properties in composite resins on light transmittance characteristics and color. Dent Mater J 26:38-44

24. Lee YK, Yoon TH, Lim BS, Kim CW, Powers JM (2002) Effects of colour measuring mode and light source on the colour of shade guides. J Oral Rehabil 29:1099-1107

25. Paul S, Peter A, Pietrobon N, Hämmerle $\mathrm{CH}$ (2002) Visual and spectrophotometric shade analysis of human teeth. J Dent Res $81: 578-582$ 